\title{
Classe social, Estado e ideologia
}

\author{
LEOPOLDO WAIZBORT
}

RESUMO: O texto reproduz uma aula para concurso junto ao Departamento de Sociologia da FFLCH-USP, na qual tentei articular o tríptico classe social, Estado e ideologia, tendo em mente a situação contemporânea empírica e teórica dos três conceitos.

\section{Estado,} trabalho, ideologia, classe, crise.

O texto reproduz, sem alterações, prova didática no concurso para professor substituto junto ao Departamento de Sociologia da FFLCH-USP em 18/02/1997.

Estados atualmente existentes, uma parte que inclusive compreende todos os Estados mais desenvolvidos e parte grandemente significativa dos demais excluindo as ditaduras e similares que se mantêm nessa década de 1990 - se caracteriza por serem Estados constitucionais que possuem, em alguma medi-

lasse social, Estado e ideologia: se a idéia é pensar os três elementos conjuntamente, ou melhor, articulá-los teoricamente de um modo mais ou menos conseqüente, sem grandes disparidades ou fissuras, é preciso reconhecer que a tarefa parece se tornar cada vez mais complexa. A semântica dos três conceitos se transforma no curso dos dois últimos séculos: veja-se, apenas a título de exemplo, as transformações do conceito de Estado quando se pensa em "Estado totalitário", ou em "Estado do Bem-estar". Ou quando se fala em "massa", frente às classes sociais. caminho, o Estado, e, a partir dele, se aproximar dos outros elementos, na tentativa de iluminar um pouco a todos, embora apenas fragmentariamente.

I. Para iniciar, poderíamos afirmar que uma parte considerável dos Professor do Departa-
mento de Sociologia da FFLCH-USP 
1 Por isso sempre se fala de "pacto" no Brasil: "pacto social", com ou sem a participação do Estado etc. da, uma oposição institucionalizada. Falar do Estado, hoje, supõe a idéia do "estado de direito". Disso se poderia desenvolver uma discussão sobre o conceito de democracia.

Esse Estado constitucional tem por característica possuir mecanismos legais e de processo que organizam os conflitos que perpassam a sociedade: tais mecanismos fazem com que esses conflitos não se tornem explosivos, e nesse sentido os normaliza. O Estado moderno, desde o século XVI, é uma instância implementadora da ordem. É isto, aliás, que lhe justifica o adjetivo "moderno": pois o próprio conceito do moderno implica, em sua história conceitual (no que diz respeito ao Estado), a idéia da “ordem", do fim da guerra - civil e entre as nações - e a idéia da paz, preferencialmente da "paz perpétua".

Então, logo de início, podemos perceber que esse Estado constitucional moderno tem por tarefa e principal característica a administração dos conflitos que perpassam a sociedade. "Administração", outras vezes "gerenciamento" dos conflitos: é a própria linguagem que testemunha o fato do Estado se aproximar da empresa. Voltarei a isto.

Para isso, esse Estado se organiza (por exemplo na divisão dos poderes, na própria organização e desdobramento institucional do Estado) e elabora procedimentos capazes de fazer com que seja possível alguma espécie de consenso nos momentos e situações conflituosas; e é dessa possibilidade e efetividade do consenso que esse Estado vive e se legitima: ele cria possibilidades para a formação de um consenso ${ }^{1}$. O Estado moderno se legitima, como disse Luhmann, enquanto procedimento.

Disso se poderia derivar um conceito mesmo de democracia (embora se trate de um conceito acentuadamente formal): ela é aquela organização política que se legitima através de procedimentos, institucionalizados, capazes de produzir consenso. À idéia do estado de direito se acrescenta a do Estado democrático. Assim, um processo de democratização de uma sociedade é um processo de organização do Estado, em que ele se organiza tendo em vista propiciar a possibilidade de resolução dos conflitos dessa sociedade, e isso é também, necessariamente, um processo de criação de procedimentos adequados à resolução desses conflitos (por isso se fala, volta e meia, sobretudo na época da Assembléia Constituinte, que é necessário fortalecer as instituições no Brasil: porque elas são instâncias do Estado e da sociedade capazes de resolver problemas). Isso, é claro, varia de acordo com a especificidade histórica de cada sociedade em questão. Notemos, à margem, que essa democracia é uma organização racional da sociedade. Isto significa: ela engendra uma racionalidade própria, que lhe é específica.

A questão da legitimidade desse Estado constitucional moderno apresenta-se, assim, como um problema permanente, pois a todo instante ele deve impedir e/ou controlar explosões oriundas desses conflitos e, de algum modo, normalizá-los. Caso isso não ocorra, esse Estado sofre uma crise de legitimidade. 
"Crise" é um componente estrutural, pode-se dizer, do Estado moderno. Ele nasce como um instrumento (procedimento!) de evitação da crise, como tentativa de contornar a guerra civil. "Crise" é "desordem", e o Estado é instância implementadora de "ordem" 2 .

"Legitimidade", por sua vez, é um conceito absolutamente - o que significa aqui: radicalmente - moderno, gerado e atribuído de sentido no moderno (cf. Blumenberg, 1988).

Administrar os conflitos da sociedade significa conservar a sociedade (se se quiser: um sistema altamente complexo), evitando que ela se desintegre ou, em outras palavras: garantir sua reprodução. Na medida em que o Estado não é capaz de resolver os conflitos, ele perde sua legitimidade, ou em outros termos, a questão da legitimidade desse Estado torna-se um problema.

II. Se assim é, os conflitos que perpassam a sociedade atual necessitam ser bem conhecidos, caso se queira compreender a natureza dessa sociedade e do Estado que lhe é correlato. Segundo Habermas, os conflitos existentes na sociedade atual são conflitos de classe (Habermas, 1983, p. 222223). Isso subentende que a sociedade moderna é uma sociedade estruturada em classes. Voltaremos a esse ponto mais à frente.

III. Diz Habermas, ao discutir os problemas de legitimação do Estado moderno:

\section{Não é particularmente surpreendente que os conflitos de classe estejam na base dos diversos fenômenos de ilegitimação; a organização estatal da sociedade é a mais importante condição de uma estrutura de classe no sentido marxiano. Naturalmente, os conflitos de legitimidade não são regularmente travados em termos de conflito econômico, mas sim no plano das doutrinas legitimadoras. Tais conflitos de legitimidade devem se ligar às definições de identidade coletiva (Habermas, 1983, p. 223) ${ }^{3}$.}

Pergunta: é a classe, hoje, definidora de identidades coletivas? Em que medida, ou até aonde? Não foram as classes enfraquecidas na sua qualidade de definidoras por excelência de identidades coletivas? Ou: quais são, hoje, as principais estratégias sociais na definição das identidades coletivas?

Além disso, a partir dessas doutrinas legitimadoras, e dessas definições de identidade coletiva, nos acercamos de outro ponto do nosso tema, a ideologia. Pois ideologia é (embora não seja só) essa doutrina legitimadora, que se situa no nível das idéias, no nível da consciência. Esse ponto será discutido em outro momento.

IV. Tentemos caracterizar, sumariamente, o Estado moderno: monopólio do uso legítimo da violência, ordem administrativa e jurídica regida por estatutos modificáveis, administração centralizada e racional, territorialidade etc. (como aprendemos com Weber). Habermas diz do Estado moderno (visto do interior), que ele

\footnotetext{
${ }^{2} \mathrm{O}$ que nos leva a pensar no "capitalismo desorganizado" de que falava Offe. Em que medida o "desorganizado" é perda da ordem, e, portanto, o primeiro passo para a desordem, vale dizer "guerra civil"? Pois nós vivemos no estado de guerra civil, conforme mostrou, de modo brilhante, Enzensberger. O Estado como implementador da ordem é o implementador da paz - a paz perpétua sempre esteve em seus planos, mas nunca foi alcançada -, mas o mundo é um mundo sem paz.

3 Grifos meus.
} 
pode ser entendido como o resultado da diferenciação de um sistema econômico, que regulamenta o processo produtivo através do mercado, ou seja, de modo descentralizado e apolítico. O Estado organiza as condições nas quais os cidadãos, enquanto indivíduos privados que atuam de modo concorrencial e estratégico, explicitam (realizam) o processo produtivo (Habermas, 1983, p. 229).

O próprio Estado só produz de modo subsidiário; $e$ isso em favor de empresários para os quais alguns investimentos funcionalmente necessários não são mais ou não são ainda rentáveis. Em outras palavras: o Estado desenvolve e garante o direito privado burguês, o mecanismo monetário, determinadas infra-estruturas, ou seja, em suma, no conjunto, as premissas para a existência de um processo econômico despolitizado (...). Já que não éo Estado a agir como capitalista, ele deve conseguir recursos necessários à sua ação a partir de rendas privadas. O Estado moderno é o Estado fiscal (Schumpeter) (Habermas, 1983, p. 229).

Há, pois, uma relação de distinção e complementação entre Estado e sistema econômico: o Estado é, ao mesmo tempo, "excluído e dependente da produção capitalista". Ele é, como disse Claus Offe, "obrigado a criar as condições e premissas formais e materiais para que a produção e a acumulação possam continuar, e para que a continuidade delas não se interrompa por causa dos fenômenos de instabilidade material, temporal e social, que são imanentes à socialização (anárquica) do processo capitalista" (Offe apud Habermas, 1983, p. 230).

É por essa razão que uma das tarefas primordiais do Estado moderno é refrear os conflitos imanentes ao processo econômico, levando-os para o âmbito do sistema político, que é o espaço institucionalizado de discussão e de busca do consenso, ou seja, da resolução de conflitos. Estado moderno implica, cada vez mais, em "sociedade civil" e "esfera pública". Sua legitimidade enquanto procedimento se ancora nelas. São espaços de regulação e controle do Estado, e também de energização, vitalização, revitalização.

Nisso está delineada a imagem do Estado social, que deve impedir "os efeitos disfuncionais secundários do processo econômico, tornando-os inócuos para o indivíduo" (Habermas, 1983, p. 234). Isso se dá pelas garantias e direitos oferecidos pelo Estado: basicamente a previdência e a educação. (Isso já é visível desde as leis do final do séc. XVIII na Inglaterra, como a Speenhamland [1795], Poor Laws etc. [cf. Polanyi, 1980; Marshall, 1967]). Assim, à idéia do Estado de direito e do Estado democrático se acrescenta a idéia do Estado do Bem-estar. 
Cito mais uma vez Habermas:

As três grandes tarefas através das quais se avalia hoje a capacidade de um governo são (1) uma política conjuntural que garanta o crescimento econômico; (2) uma ação orientada para as necessidades coletivas e que influencie a estrutura produtiva; (3) $e$ as correções que devem ser efetuadas na rede das desigualdades sociais. O problema não está no fato de que tais tarefas se imponham ao Estado e que ele seja obrigado a assumi-las programaticamente; o conflito, no qual se pode ver uma fonte dos problemas de legitimação, reside antes na necessidade de que o Estado realize todas essas tarefas sem quebrar as condições funcionais de uma economia capitalista, ou seja, sem tocar na relação de complementaridade que exclui o Estado do sistema econômico, no momento mesmo em que o torna dependente da dinâmica de tal sistema (Habermas, 1983, p. 235).

Resumidamente, em outras palavras o dilema é este: a partir de quando e até onde deve o Estado intervir?

Essa é uma questão central, que se coloca tanto ao nível da teoria como ao nível da prática. E se coloca a todos nós: pois o modo como o Estado encara e resolve (ou tenta resolver) esse problema atinge a cada indivíduo. Emprego e desemprego, previdência social, saúde, educação: tudo isso diz respeito e atinge à todos.

V. Mais atrás havia afirmado, citando Habermas, que os conflitos que perpassam a sociedade contemporânea são conflitos de classe. Vejamos isto um pouco mais de perto.

Marx, num texto clássico ( $O$ Capital, cap. 52), definiu que na sociedade capitalista havia três grandes classes: a classe dos capitalistas, a classe dos assalariados e a classe dos proprietários da terra. Poderíamos, hoje, afirmar que essas três classes são as classes da sociedade contemporânea?

Ou, nos termos já mencionados, são elas os parâmetros definidores de identidades coletivas?

Responder "sim" significa que consideramos a sociedade atual como uma sociedade capitalista; em outras palavras, em que predomina o modo de produção capitalista. É claro que o capitalismo hoje não é tal qual o capitalismo no tempo de Marx; mas aceitar que vivemos num capitalismo avançado significa que as estruturas e formas básicas do capitalismo não somente ainda estão presentes na sociedade hoje, como ainda a organizam e determinam. Muito simplificadamente, vamos considerar que essa sociedade capitalista se caracteriza por uma oposição irreconciliável entre capital e trabalho - oposição que existe porque o capital expropria o trabalho, ou em outras palavras, o capital tira do trabalho mais do que lhe dá. Responder "sim" significa, então, 
que podemos caracterizar as classes da nossa sociedade através dessas três grandes categorias de "assalariados", "capitalistas" e "proprietários de terra".

Responder "não" significa que consideramos que a sociedade atual não é uma sociedade capitalista, mas sim uma sociedade que poderíamos designar, digamos, como sociedade industrial. Essa sociedade é fundamentalmente diferente da sociedade capitalista porque ela atingiu um patamar de desenvolvimento substancialmente distinto: o grande incremento da indústria no nosso século, assim como o caráter altamente planejado de todos os aspectos da economia, fazem com que aquela oposição irreconciliável entre capital e trabalho torne-se não mais irreconciliável, mas passível de uma convivência mais calma e até mesmo harmoniosa: "amaciamento" e "enfraquecimento" da luta de classes. O Estado industrial poderia ser caracterizado por uma sociedade em que capital e trabalho, embora distintos, têm interesses comuns, e por isso trabalham de "mãos dadas". O que não significa excluir as zonas de conflito.

Mesmo posta nesse nível de simplificação, essas respostas não nos podem satisfazer. Isso porque a sociedade moderna conjuga aspectos de uma sociedade capitalista avançada com aspectos de uma sociedade industrial. Seria o caso de lembrar a sugestão de Adorno: fazer a crítica de uma com a outra, e vice-versa. Aceitar que a sociedade é uma sociedade industrial que superou a oposição entre capital e trabalho é afirmar que chegamos a uma harmonia entre capital e trabalho, em que cada um dá ao outro o que lhe é direito, e que, portanto, não há conflito. Todos nós podemos, com nossa experiência mais restrita, perceber que a sociedade contemporânea não conseguiu, e está muito longe de chegar a uma tal harmonia. Mesmo nos países mais desenvolvidos há conflitos, aos quais cabe (como vimos) ao Estado propiciar solução. Por outro lado, se a nossa sociedade é substancialmente uma sociedade capitalista, isso supõe que a oposição irreconciliável entre trabalho e capital persiste. Mas para pensarmos capitalismo hoje não podemos deixar de lado a realidade que tomou corpo com o Estado do Bem-estar social: um Estado, típico do pós-guerra nos países desenvolvidos, que operou uma pacificação no conflito das classes, através de uma política que procurava garantir alguns pontos básicos que vimos ser o objetivo do Estado moderno: garantia o trabalho, o tempo livre e a segurança de cada um dos indivíduos. Na verdade, podemos ver nesse Estado uma imagem desenvolvida daquele Estado do final do séc. XVIII, que garantia pela primeira vez certos benefícios aos trabalhadores. Se pensarmos assim, esse Estado poderia ser a forma atual da sociedade capitalista. O Estado moderno implementa uma série de benefícios que tornam menores as disparidades entre os indivíduos: nos Estados mais desenvolvidos, todos têm (ao menos potencialmente) casa, educação, saúde etc. Se todos possuem esses "bens", aquele conflito irreconciliável torna-se cada vez menos violento.

Mas, ao mesmo tempo, há elementos que nos mostram imediatamente que o conflito persiste, e com intensidade. Uma das coisas que nos 
permite constatá-lo do modo mais pungente é o desemprego. No esquema capitalista clássico, era necessário ao capital a existência de um exército de reserva, que impedia que o custo do trabalho (da força de trabalho) subisse além dos interesses do capital: o capitalista sempre podia despedir seu empregado e contratar outro, pagando-lhe menos. Assim, já na configuração clássica do capitalismo, havia um grupo significativo de indivíduos formado por desempregados. Hoje, esse grupo não só se mantém, como se amplia e tende a se ampliar cada vez mais.

O relatório “O emprego no mundo 1996-1997” da OIT, divulgado no final de novembro de 1996 (cf. O Estado de S. Paulo, 26/11/96, p. B14), assinala que $30 \%$ de toda a mão-de-obra mundial está à margem do mercado de trabalho. Isto significa que há hoje, no mundo, cerca de 1 bilhão de desempregados. Em São Paulo, uma pesquisa Seade-Dieese afirmou que o índice de desemprego na Grande São Paulo cresceu 7,6\% entre dezembro de 95 e dezembro de 96 . Em média, $15,1 \%$ da população economicamente ativa permaneceu sem emprego ao longo do ano.

Isto parece se relacionar com o enfraquecimento do Estado do Bemestar que, com sua função redistributiva, parecia engendrar, ou ao menos pretendia envolver, a esfera do trabalho em um mundo tranqüilo. (Não estou afirmando, é claro, que tal Estado tenha se consolidado no Brasil, ao citar os números de São Paulo, e nem no mundo como um todo.)

Um ponto importante parece dizer respeito ao envelhecimento do trabalho enquanto categoria-chave explicativa.

No curso do século passado e início deste, o trabalho tornou-se uma categoria fundamental e determinante para a compreensão do mundo, do mundo moderno. Ele se tornou "a substância da vida da sociedade burguesa" (Löwith, 1978, p. 284), e por isso ele foi objeto da reflexão - em Hegel, Marx, Nietzsche, Kierkegaard etc.

H. Arendt, por sua vez, afirmou já há quase meio século: “A era moderna trouxe consigo a glorificação teórica do trabalho, e resultou na transformação efetiva de toda a sociedade em uma sociedade operária. (...) O que se nos depara (...) é a possibilidade de uma sociedade de trabalhadores sem trabalho, isto é, sem a única atividade que lhes resta. Certamente nada poderia ser pior" (Arendt, 1981, p. 12-13). Entretanto, só mais tarde esse diagnóstico, proferido na década de 1950, foi apropriado pela sociologia.

Assim, C. Offe vai afirmar que, neste último quarto do século, o "poder determinante abrangente do fato social trabalho (assalariado) e de suas contradições (...) se tornou sociologicamente questionável” (Offe, 1989,p. 171).

Na estrutura e no processo da sociedade, o trabalho e os trabalhadores não surgem mais, como antes, como um princípio fundamental que "ordena" ou "determina" ou "organiza" a sociedade.

Trata-se da implosão da categoria do trabalho. Aque se deve isto? E em que medida isto afeta o Estado e as classes?

Um dos pontos que explica a perda da centralidade da categoria do 
trabalho, como diz Offe, é o fato de que a esfera da produção parece estar perdendo sua importância enquanto determinante na estrutura da sociedade. O setor secundário parece diminuir suas necessidades de trabalhadores, enquanto o setor terciário é o setor que se amplia.

Veja-se o exemplo norte-americano, no que diz respeito ao setor industrial: nos EUA, segundo previsões levantadas por Andre Gorz, a indústria fornecerá no final do século emprego para $10 \%$ da população ativa, o que significa que os salários distribuídos pelo setor secundário atingem apenas $10 \%$ da população ativa (cf. Gorz, 1990, p. 213). E os outros 90\%?

O setor terciário surge como grande empregador, e, portanto, como grande distribuidor de salários. Gorz se pergunta: mas onde se cria valor nesses serviços do setor terciário? (cf. Gorz, 1990, p. 213).

A isto acresce o fato de que a criação de empregos no setor terciário é sobretudo criação de empregos de baixa e baixíssima remuneração (cf. Gorz, 1990, p. 213).

A pesquisa mencionada Seade-Dieese atestou, para a Grande São Paulo, que a maioria dos serviços criados no período são empregos que requerem pouquíssima ou nenhuma qualificação e são muito mal remunerados, além de se caracterizarem por alta rotatividade: são mais temporários que fixos.

E o "trabalho", as categorias que ele implica e nas quais ele se deixa circunscrever não se aplicam tão clara e adequadamente ao terciário como ao secundário. A identidade que o trabalho classicamente fornecia dizia respeito sobretudo ao trabalho industrial, e frente à "prestação de serviços" ela se torna rala e, ao mesmo tempo, opaca. O trabalho torna-se como que "difuso".

Eu cito Claus Offe:

Os critérios de racionalidade desenvolvidos para a utilização e controle da força de trabalho na produção capitalista de mercadorias só podem ser transferidos para a 'produção' de ordem e normalidade realizada pelos serviços dentro de estreitos limites (...) É esta diferenciação dentro do conceito de trabalho que (...) parece constituir o ponto de apoio mais importante do argumento segundo o qual não se pode mais falar de um tipo de racionalidade basicamente unificado que organize e governe toda a esfera do trabalho (Offe, 1989, p. 180).

Weberianamente, com o processo de diferenciação no interior da esfera do trabalho temos o surgimento de sub-esferas que engendram legalidades próprias: em outros termos: uma racionalidade própria, que no caso significa uma racionalidade outra do que a que regulava o conceito de trabalho anterior. Temos, então, um conflito de racionalidades diferentes no interior do mundo do

4 Sobre a ambigüidade do trabalho, cf. Waldenfels (1990, p. 151 ss.). trabalho. Isto resulta na sua fragmentação. É ainda neste contexto que se pode afirmar que o trabalho torna-se crescentemente ambíguo ${ }^{4}$.

Um outro ponto relativo ao envelhecimento do trabalho diz respei- 
to ao enfraquecimento da ética do trabalho.

1) perda do poder das tradições religiosas e seculares que prescreviam o trabalho como "dever".

2) hedonismo consumista crescente.

3) desvalorização do "fator humano" do trabalho: criatividade, experiência, conhecimento.

4) rompimento do nexo entre trabalho e vocação e sua distinção crescente.

5) a esfera do trabalho serve cada vez menos como parâmetro para outras esferas da vida.

6) diminuição das horas de trabalho na vida das pessoas e conseqüente surgimento e desenvolvimento de outros interesses.

7) a perda da importância e do papel central do trabalho relativizam seu papel como elemento de identidade social e individual.

8) o crescimento do desemprego, não conjuntural, mas estrutural, o torna uma experiência normal e comum, e não mais exceção.

O resultado disto tudo é que o trabalho é um dos principais centros de conflito e, portanto, de tarefas regularizadoras para a manutenção da legitimidade do Estado moderno - ao lado da pobreza, da devastação do meio ambiente e da desigualdade. Note-se, de passagem, que estes quatro grandes conflitos não se deixam subsumir simplesmente às visões costumeiras de classe social.

Como disse Offe, a "consciência social" não se articula mais como "consciência de classe" (Offe, 1989, p. 194).

Ou, para falar nos termos já mencionados: Classe não é mais fundamental na formação da identidade ${ }^{5}$.

No mundo contemporâneo há uma redefinição de "classe" paralela e concomitante à redefinição de "trabalho" apontada por Offe (i.e., a perda da racionalidade central e única). Em outros termos: se o trabalho perde o papel de categoria central, a classe acompanha homologamente esse movimento. Mas: as diferenças de classe se convertem, em parte-numa parte e num aspecto importante-, a meu ver, na diferença entre os que têm e os que não têm trabalho: insiders e outsiders.

A crise do Estado do Bem-estar ou keynesiano significou historicamente o descomprometimento do Estado com o compromisso do pleno emprego. Isto ocorreu na Europa e nos EUA na década de 70. Parece não ser politicamente possível nem ecologicamente desejável que se possa ressuscitar a idéia do pleno emprego. Assim, o modelo do Estado de Bem-estar, que distribuía a força de trabalho e a renda, torna-se um problema: crise de legitimidade do Estado moderno.

A distribuição do trabalho é um desafio frente aos grupos/segmentos "marginalizados": os imigrantes, as mulheres. São eles os afetados, inicialmente, com o decréscimo da oferta de emprego (na França, Le Pen e seus aliados querem punir quem fornecer trabalho a estrangeiros). 
Neste ponto reencontramos as afirmações de Gorz acerca do tipo de empregos que são gerados no setor terciário, pretensa saída para os problemas (consideráveis) para o Estado gerados com o desemprego. Diz Gorz:

Os 'novos empregos terciários' significam essencialmente obrigar milhões de homens e mulheres a disputarem-se o privilégio de vender seus serviços pessoais, freqüentemente abaixo do salário horário mínimo, àqueles, cada vez menos numerosos, que conservam um emprego bem pago (Gorz, 1990, p. 213).

Gorz afirma ainda que, ao final do século, $75 \%$ da população ativa é composta por trabalhadores precários ou marginais:

Um membro do Instituto de Ciências Econômicas e Sociais (WISO) da União dos Sindicatos Alemães (DGB), Wolfgang Lecher, considera plausível a seguinte estrutura da população ativa: $25 \%$ de trabalhadores qualificados permanentes e protegidos; $25 \%$ de assalariados pouco qualificados, empregados de maneira precária por empresas de sub-contratação e de serviços; $50 \%$ de marginais trabalhando apenas ocasionalmente ou raramente (Gorz, 1990, p. 217, nota).

Uma tal estruturação é um foco constante de crise de legitimidade para o Estado moderno, que se quer universalizante. Sua pretensão de universalidade esbarra imediatamente com os efeitos perversos de desigualdade (desigualdade potencialmente, se não realmente, enorme) dessa distribuição.

Afirmação semelhante é feita por C. Deutschmann, do Institut für Sozialforschung de Frankfurt-junto-ao-Main: "O que parece estar se desenvolvendo como o problema social dominante do futuro não são os conflitos trabalhistas gerados pela 'subordinação real', mas uma escassez geral de trabalho, a impossibilidade de basear a segurança social no trabalho" (apud Offe, 1989, p. 88).

O resultado disto é: uma divisão da sociedade entre trabalhadores plenos e desempregados e sub-empregados, excluídos da sociedade do trabalho. A pergunta é: esta bipartição é a nova estrutura de classes do Estado pósestado do Bem-estar?

Ligado a isto, um outro ponto significativo na fragilizada base de legitimidade do Estado: o problema da distribuição da renda.

A concentração de renda parece ser o destino que acompanha a bipartição do trabalho entre aqueles que o possuem e aqueles que se acham dele privados. Veja-se o que diz Paul Krugman, um economista do MIT:

A impressão popular de que a primeira geração do pós-guerra passou por uma imensa melhoria nos 
padrões de vida, ao passo que a segunda não, permanece correta; o sonho americano pode não estar morto, mas certamente já não é o que era. I Para completar, enquanto os trabalhadores, como grupo, partilharam plenamente dos ganhos de produtividade, não o fizeram de maneira eqüitativa. A evidência esmagadora de um imenso aumento na desigualdade de renda nos EUA nada tem que ver com índices de preço e, portanto, não é afetada pelas recentes revelações estatísticas. Ainda é verdade que famílias do quinto e último estrato, que tinham 5,4\% da renda total em 1970, tinham apenas 4,2\% em 1994. No mesmo período, a participação dos $5 \%$ no topo da pirâmide de renda aumentou de 15,6\% para 20,1\%. / Também é verdade que corporações, que costumavam ganhar até 35 vezes mais que seus empregados, agora ganham 120 vezes mais. $O$ padrão de vida da maioria das pessoas pode ter crescido em termos absolutos, mas essas disparidades de crescimento ainda tornam crescentemente questionável se faz sentido pensar em nós mesmos como sociedade de classe média. E, apesar das revisões, não há muita dúvida de que a incidência de pobreza realmente acentuada nos EUA aumentou, não diminuiu, na geração passada (Krugman, 1997).

O que este economista retrata são as diferenças do Estado do Bemestar em seu apogeu e seu esgotamento. O Estado vê-se confrontado com problemas graves, na medida em que o pretenso pleno emprego não pode mais ser pretendido - dados os altos custos que implicaria.

Vejamos um outro exemplo que conjuga a questão da distribuição, concentração da renda e desenvolvimento tecnológico e reitera as afirmações de Andre Gorz. Edward Amadeo, em um texto publicado em dezembro de 1996 intitulado "Tecnologia e distribuição de renda", afirma: "Há fartas evidências de que na Europa Ocidental e nos EUA tem crescido a disparidade de renda entre trabalhadores com maior nível de instrução e com menor nível de instrução. Dito de outra forma, o retorno da educação tem crescido, premiando os mais educados. Essa tendência tem um efeito distributivo perverso à medida que, mesmo em países em que o acesso à educação é igualitário, os filhos de famílias pobres são em geral menos educados que os filhos de famílias ricas. Logo, o aumento da disparidade entre educados e menos educados piora a distribuição de renda" (Amadeo, 1996).

A diferença entre trabalhadores com maior nível de instrução e trabalhadores com menor nível de instrução se reproduz a seguir como a diferença entre trabalhadores e não-mais-trabalhadores, pois que perderam 
suas possibilidades de inserção no mercado de trabalho em função das razões apontadas.

O Estado social propiciou aos trabalhadores um certo rendimento que permitia sua subsistência, assim como lhes forneceu previdência social e educação. Mas ele não pôde garantir o direito ao trabalho, porque isso significaria que todos poderiam trabalhar e, com isso, romper-se-ia o exército de reserva. (A questão não é, como poderia parecer, que não haja trabalho para todos, pois poder-se-ia simplesmente fazer com que todos trabalhassem menos.) Hoje, um dos pontos mais conflituosos que podemos detectar na sociedade é o direito ao trabalho - ou, formulado em outro ponto, a questão daqueles que não possuem trabalho. Nessa questão, o Estado é chamado ao palco.

Com a revolução eletrônico-tecnológica dos últimos anos, os processos de trabalho foram (e se não foram podem ser) e estão sendo modificados grandemente. Hoje, por isso, é possível uma grande economia de trabalho, em função das máquinas. Com isso, tendencialmente pode-se esperar uma diminuição do número de empregados, e, conseqüentemente, um aumento dos desempregados. Nessa sociedade, o conflito entre aqueles que não tem trabalho e a busca de um trabalho que lhes é negado assume um papel de destaque.

Temos assim duas classes: ocupados e desocupados. Aqueles são os que estão ligados a um núcleo produtivo, estes os que estão excluídos da produção, marginalizados, excluídos (cf. Habermas, 1985, p. 70): como diz Gorz, a "não-classe dos não-trabalhadores".

O relatório “O emprego no mundo 1996-1997” da OIT também chama a atenção para esse mesmo fenômeno, a crescente desigualdade salarial: poucos empregados ganham mais, enquanto a maioria ganha menos.

O desenvolvimento tecnológico propicia a substituição de trabalhadores menos qualificados por trabalhadores cada vez mais qualificados - vale dizer, que obtiveram uma formação profissional através de estudo. Se efeitos distributivos perversos são perceptíveis em nações onde o acesso à educação é universalizado, o que pensar em nações, como o Brasil, onde a educação é um privilégio?

Em todos estes pontos nos confrontamos com problemas de legitimação do Estado moderno.

Retomemos, uma vez mais, C. Offe:

Uma vez que não existem alternativas viáveis para 'trabalhar'e 'viver' do trabalho, o 'excedente' da força de trabalho continua a se acumular, em um alto e sempre crescente grau, exatamente no lugar em que não pode ser utilizado: no lado da oferta do mercado de trabalho. Assim, as instituições do Estado de bemestar destinadas a dar apoio aos desempregados, aos que ainda nãoforam empregados e aos aposentados 
antes do tempo se encontram diante de problemas fiscais contínuos, e fincando-se os alicerces para um conflito pelo menos latente entre, de um lado, empregados e empregadores - que são oprimidos respectivamente com os crescentes impostos e com as elevadas taxas de previdência social-e, de outro, os desempregados (Offe, 1989, p. 125) ${ }^{5}$.

$S e$ assim é, a clivagem do conflito de classe entre trabalho e capital está transformada. Agora, trabalho e capital solidarizam-se porque têm interesses comuns - menos impostos e menor carga tributária e previdenciária -, que estão em contraposição aos interesses dos que não têm emprego.

Em meio a isto, as finanças do Estado desmoronam. O que leva a outro ponto de crise na sua legitimação.

Os problemas do trabalho e do emprego e desemprego levam a um questionamento do modelo keynesiano do Estado de Bem-estar, ao mesmo tempo em que apresentam problemas a serem resolvidos pela democracia e por uma sociedade democrática.

Em relação à capacidade do Estado em gerenciar os problemas que são postos pela questão do trabalho, poderíamos perguntar, com Habermas (cf. Habermas, 1985, p. 148), em que medida o Estado, por meio de medidas legais e burocráticas, é capaz de trazer, proporcionar e garantir novas condições de vida?

Como mostrou Offe, estado de direito, estado democrático e estado do bem-estar não se harmonizam pura e simplesmente, senão que dão margem e espaço a inúmeras tensões, que temos de elaborar teoricamente e enfrentar praticamente. Os limites e as vantagens desses três estados estão postos para a reflexão; até onde vai e até onde deve ir o estado democrático, e o mesmo em relação ao estado de bem-estar, são questões que estão na ordem do dia.

A definição do papel do Estado passa, portanto, por uma definição das suas atribuições e limites. A questão do trabalho é aqui um desafio, se pensarmos nas alternativas frente ao problema da distribuição da renda/ distribuição social da riqueza. Há alternativas mais conservadoras, tais como o imposto de renda negativo, que garante uma renda mínima; e alternativas mais transformadoras, como a que garante um trabalho mínimo, que por sua vez garante a participação na produção e conseqüente distribuição social da riqueza (Gorz).

Se o Estado está envolvido em problemas de legitimação, o problema da justiça distributiva está fincado em seu âmago, pelo menos desde que se começou a falar em estado de direito, estado democrático e estado do bemestar. Se assim é, um dos grandes desafios do Estado contemporâneo é a questão do trabalho, que engendra conflitos que põe a sua legitimidade em foco: como distribuir trabalho e as riquezas oriundas dele?

Com isso, a questão do Estado se articula também com a questão

5 Grifo meu. 
da classe: parece que haveria um remanejo da própria idéia de classe, e a cisão entre trabalhadores e não-trabalhadores é, hoje, mais candente do que um conflito entre, digamos, burguesia e proletariado. O que nos leva a indagar, seguindo Koselleck, se não há uma transformação na semântica de "classe" na contemporaneidade.

Todas essas transformações indicam-nos que também em relação às classes talvez tenha havido transformações. Por isso, a discussão das classes na sociedade contemporânea é um dos importantes temas da pesquisa sociológica, em que convivem interpretações que vão da reprodução do esquema de Marx até a afirmação de que não há mais classes.

Nisso há também que assinalar um novo fenômeno, típico dos últimos anos: os novos movimentos sociais. Aglutinados em torno de necessidades, interesses e ideais comuns, indivíduos passaram a se organizar em movimentos reivindicatórios que antes não eram sequer supostos. Os movimentos de mulheres, homossexuais, minorias em geral, ecológico etc. dão disto testemunho eloqüente.

E, mais que classes, são eles que articulam definições de identidades coletivas. E, portanto, são eles que se põem como inquiridores da legitimidade do Estado contemporâneo e demandantes de suas políticas.

Esses novos movimentos sociais aparecem como instrumentos de repolitização do domínio público e de revitalização da esfera pública e da sociedade civil.

Os novos movimentos parecem exigir, em última instância, uma redefinição dos procedimentos do Estado moderno, em um sentido que parece fortalecer a idéia de democracia. Mas são eles uma tendência forte o suficiente?

Segundo Habermas, é justamente nos interstícios entre sistema e mundo da vida que se desenvolvem os novos potenciais de resistência, emancipação e protesto nas sociedades avançadas:

Nas sociedades desenvolvidas do ocidente desenvolveram-se conflitos nas duas últimas décadas [ele escreve em 1981, LW] que em muitos aspectos se desviam do padrão de conflito em torno da distribuição, que o Estado social institucionaliza. Tais conflitos já não se produzem nos âmbitos da reprodução material, já não se canalizam através de partidos e associações, nem tampouco podem ser apaziguados recorrendo a compensações conforme o sistema. Os novos conflitos surgem antes em âmbitos da reprodução cultural, da integração social e da socialização; desenvolvem-se em formas de protesto subinstitucionais, em todo caso extra-parlamentares; $e$ no déficit subjacente se reflete uma coisificação dos âmbitos de ação estruturados comunicativamente, ao qual não se pode fazer frente através dos meios di- 
nheiro e poder [isto é, dos sistemas economia e política, LW]. Pois não se trata primariamente de compensações que o Estado social possa outorgar, mas sim da defesa e restituição de formas de vida em perigo ou da implementação de formas de vida reformadas. Em suma, novos conflitos não surgem em torno de problemas de distribuição, mas sim em torno de questões suscitadas por uma gramática das formas de vida (Habermas, 1988, p. 576).

Habermas tem em vista os movimentos ecológico, antinuclear, pacifista, feminista, homossexual; as experiências de vida comunal, rural, estilos de vida alternativos; proliferação de seitas religiosas, grupos de auto-ajuda etc.

Entretanto, ao mesmo tempo, este diagnóstico de 1981 parece subestimar os já mencionados conflitos distributivos que perpassam o Estado moderno.

Resta abordarmos, finalmente, a questão da ideologia. Nas sociedades capitalistas avançadas os conflitos políticos e econômicos são diluídos através de mecanismos de alienação que transformam o indivíduo em cliente das burocracias estatais dominantes. Diz Habermas:

As conseqüências que resultam da institucionalização de um modo alienado de participação política se deslocam até o papel de cliente; assim como as cargas da normalização do trabalho alienado se deslocam até o papel do consumidor (Habermas, 1988, p. 515).

Ambas as alienações são compensadas com valores economicamente produzidos. O problema é como formular a questão da ideologia de modo conseqüente com as formulações precedentes. Se se aceita o que foi dito, é preciso então conceder a Habermas a precedência de sua formulação a esse respeito:

No lugar da 'falsa' consciência aparece hoje a consciência fragmentada, que evita o esclarecimento acerca do mecanismo da reificação. Só com isso são preenchidas as exigências de uma colonização do mundo da vida: os imperativos dos subsistemas autônomos, assim que eles são despidos de seu véu ideológico, invadem de fora o mundo da vida (...) e forçam a assimilação. Mas as perspectivas dispersas da cultura natal não se deixam coordenar a tal ponto que o jogo das metrópoles e do mercado mundial possa ser descoberto a partir da periferia. / Uma teoria da reificação capitalista-tardia, reformulada nos conceitos de sistema e mundo da vida, necessita 
portanto de complementação mediante uma análise da modernidade cultural, que toma o lugar de uma superada teoria da consciência de classe. Em vez de servir à crítica da ideologia, ela deveria esclarecer o empobrecimento cultural e a fragmentação da consciência cotidiana; ao invés de perseguir os traços dispersos de uma consciência revolucionária, ela deveria investigar as condições para um reacoplamento da cultura racionalizada com uma comunicação cotidiana que necessita das tradições vitais (Habermas, 1988, p. 522).

Habermas critica o fato de que o mundo da vida se subordina (é claro que involuntariamente) aos imperativos colonizadores do sistema:

1) os elementos prático-morais são expulsos das esferas da vida privada e pública;

2) a vida cotidiana se monetariza e burocratiza;

3) tudo é subordinado aos imperativos do sistema econômico e administrativo.

4) o mundo da vida, colonizado pelo sistema, fica com sua reprodução simbólica ameaçada.

A saída habermasiana é, portanto, a descolonização do mundo da vida, a reconquista de sua soberania. O que não deixa de parecer, aos meus olhos, como um reencantamento do mundo.

Recebido para publicação em agosto/1997

WAIZBORT, Leopoldo. Social class, State and ideology. Tempo Social; Rev. Sociol. USP, S. Paulo, 9(2): 65-81, may 1998.

UNITERIMS:

State,

work, ideology,

class,

crisis.
ABSTRACT: This text reproduces a lecture given in the scope of an examination at the Sociology Department of the FFLCH-USP. For the presentation I have tried to articulate the three concepts "social class", "State" and "ideology" by taking into consideration their actual empirical and theoretical situation. 


\section{REFERÊNCIASBIBLIOGRÁFICAS}

Amadeo, Edward. (1996) Tecnologia e distribuição de renda. O Estado de S. Paulo, 23/12.

Arendt, Hannah. (1981) A condição humana. São Paulo, Edusp, .

BECK, Ulrich. (1986) Risikogesellschaft: auf dem Weg in eine andere Moderne. Frankfurt a. M., Suhrkamp.

Blumenberg, Hans. (1988) Die Legitimität der Neuzeit. Frankfurt a. M., Suhrkamp. 2, Ausg.

Gorz, André. (1990) Quem não tiver trabalho, também terá o que comer. Estudos avançados, 4(10):211-228, set-dez.

Habermas, Jürgen. (1983) Para a reconstrução do materialismo histórico. São Paulo, Brasiliense. . (1985) Die Neue unübersichtlichkeit. Frankfurt a. M., Suhrkamp. . (1988) Theorie des kommunikativen Handelns. Vol. 2. Frankfurt a. M., Suhrkamp.

Krugman, Paul. (1997) Nova matemática, a mesma história. O Estado de S. Paulo, 25/01, p. B2.

Löwith, Karl. (1978) Von Hegel zu Nietzsche. Hamburg, Felix Meiner.

Marshall, T.H. (1967) Cidadania, classe social e status. Especialmente o cap. III: "Cidadania e classe social". Rio de Janeiro, Zahar.

MarX, K.(1985) O Capital. Vol. 3. São Paulo, Ed. Abril.

OfFE, Claus. (1989) Capitalismo desorganizado. São Paulo. Brasiliense.

Polanyi, K. (1980) A grande transformação. Rio de Janeiro, Campus.

WALDENFELs, Bernhard. (1990) Ambivalenz der Arbeit. In: Der Stachel des Fremden. Frankfurt a. M., Suhrkamp. 2, Aufl, p. 151-172. 